\title{
El Partido Socialista de Chile y la presente cultura de facciones. Un enfoque histórico generacional $(1973$ - 2015)
}

\author{
The Socialist Party of Chile and the current culture of factions. A generational \\ historical approach (1973 - 2015)
}

Víctor Muñoz Tamayo*

\begin{abstract}
Resumen: El artículo analiza dos generaciones militantes del Partido Socialista de Chile y su comprensión, identidad y percepción relativa a la estructura de facciones que caracteriza a dicho partido. Desde un enfoque histórico (19732015) y generacional (comparaciones entre grupos etarios a partir de elementos derivados de las diacronías histórico - biográficas), y desde una investigación cualitativa, se busca comprender los cambios contemporáneos de la cultura militante socialista.
\end{abstract}

Palabras Clave: Generaciones - Cultura militante - Partido Socialista de Chile - Facciones.

\begin{abstract}
The article analyzes two militant generations of Chilean Socialist Party and its understaning, identity and perception on the structure of features that characterizes this party. From a historical (1973-2015) and generational perspective (comparisons between age groups from elements derived from historical and biographical evolution) and from a qualitative research, this article seeks to understand contemporary changes of the militant socialist culture.
\end{abstract}

Keywords: Generations - Militant culture - Chilean Socialist Party - Factions

\section{Introducción}

Este texto busca otorgar una perspectiva histórica al conocimiento del presente del Partido Socialista de Chile, particularmente en lo referido a un elemento constante en su cultura

\footnotetext{
* Chileno. Doctor en Estudios Latinoamericanos UNAM. Investigador Centro de Estudios de la Juventud CEJU - Universidad Católica Silva Henríquez UCSH. Este trabajo se enmarca en el proyecto FONDECYT Iniciación número 11140307, tres años de duración y titulado: "Generaciones, cultura militante y faccionalismo en los partidos Socialista y Demócrata Cristiano de Chile. Cambios contemporáneos en las nociones de "la política", "el partido" y su vinculación con la sociedad. 1973 - 2015", UCSH. vmunozta@gmail.com
} 
política: el faccionalismo. Se asume que los militantes actuales poseen trayectorias desde las cuales fundamentan su comprensión e interpretación del presente partidario, por lo mismo, pensamos que es central lo generacional como factor etario - histórico que interviene en las percepciones y sentidos identitarios de la militancia. En definitiva, se propone destacar el fenómeno generacional como elemento que determina distinciones en una cultura militante, y en tanto manifestación de una historia reciente que ha sido subjetivizada y convertida en relato de identidad por sus actores.

Desde su fundación en 1933, el PS reunió a personas y agrupaciones militantes de diversa identidad doctrinaria (social demócratas, marxistas, anarquistas, trotskistas, antioligarcas latinoamericanistas) y social (sectores populares - obreros, sectores medios estudiantiles, profesionales e intelectuales), lo que derivó en la proliferación de grupos que expresaban las múltiples identificaciones sociopolíticas coexistentes. ${ }^{1}$ Por lo mismo, no es una novedad decir que el PS siempre ha sido una organización faccionada, y que en su historia ha habido momentos en que los subgrupos y liderazgos asociados coexisten en unidad orgánica, así como coyunturas en que proliferan entidades socialistas autónomas. Sin embargo, el carácter faccional ha estado sujeto a transformaciones, y el tipo de cuestiones que han deslindado a los subgrupos internos del socialismo ha cambiado, tanto por los procesos internos del PS como por su conexión con los cambios de la política a nivel general en la sociedad chilena.

En el transcurso de los últimos 40 años, fenómenos como el clima de consensos relativos a la transición política y el modelo económico, los equilibrios de fuerzas determinados por los llamados "enclaves autoritarios" y el modelo electoral binominal ${ }^{2}$, la crisis del marxismo en la izquierda, y el tránsito desde un desarrollismo con eje en el Estado y la política, hacia un neoliberalismo de orientación tecnicista y despolitizadora, han repercutido en las dinámicas militantes de los partidos políticos chilenos ${ }^{3}$. Cabe entonces la pregunta por si estas transformaciones han incidido también en el modo en que la subjetividad militante socialista asume las lógicas y los sentidos que configuran sus agrupamientos internos.

\footnotetext{
${ }^{1}$ Ver: Paul Drake, Socialismo y populismo. Chile 1936 - 1973, Valparaíso, Instituto de Historia UCV, 1992. Julio Cesar Jobet, Historia del Partido Socialista de Chile, Santiago, Documentas, 1987.

${ }^{2}$ Por enclaves autoritarios se entendieron: la existencia de los "senadores designados" y "senadores vitalicios" (que incluyeron al propio Pinochet en 1998 en tanto ex presidente), la inamovilidad de las comandancias en jefe de las fuerzas armadas (que implicó tener al ex dictador dirigiendo el ejército hasta 1998) y las atribuciones y carácter del Consejo de Seguridad Nacional (y su influencia en la composición del Tribunal Constitucional). En el sistema electoral binominal una mayoría debe doblar en votos como pacto a la segunda mayoría a fin de marcar un desequilibrio de fuerzas a su favor, pues de lo contrario las dos candidaturas electas se reparten entre los dos pactos más votados. Los enclaves autoritarios, sumados a los efectos del sistema binominal en la representación parlamentaria, fueron el escenario forzado de la llamada "política de los consensos" y de aquel límite a las expectativas que Aylwin denominó: "la medida de lo posible".

${ }^{3}$ Manuel Antonio Garretón, Del pinochetismo a la sociedad democrática. Globalización y política en el bicentenario, Santiago, Debate, 2007. Tomás Moulián, Chile actual. Anatomía de un mito, Santiago, Lom, 1998. Verónica Valdivia, Rolando Álvarez Vallejos, Karen Donoso, La alcaldización de la política. Los municipios en la dictadura pinochetista, Santiago, Lom, 2012.
} 
En relación a esta pregunta, el año 2009 un estudio de los cientistas políticos Ricardo Gamboa y Rodrigo Salcedo ${ }^{4}$ advirtió sobre un cambio significativo en los elementos que definían las diferencias entre los grupos internos del PS desde la década del 90 hasta el año 2003, periodo en que este partido se mantuvo como tienda oficialista. Sus conclusiones apuntaban a que en el fenómeno faccional del PS predominaba la diferenciación por cuestiones estratégicas o tácticas en términos operativos, como la forma de establecer la relación con el gobierno o el modo de articular la organización partidista, y había disminuido drásticamente la importancia de los aspectos ideológicos y programáticos. Lo anterior suponía un gran consenso político al interior del PS, y una dinámica interna en que las facciones organizaban sus alianzas según las oportunidades circunstanciales y en virtud de "opciones estratégicas", por lo que en la disputa por la conducción socialista era posible cualquier tipo de alianza instrumental entre los subgrupos, no existiendo en ello lógicas de correlación más permanentes y relativas a las posiciones políticas.

Teniendo como punto de partida los aportes de Gamboa y Salcedo, hemos querido ahondar en el fenómeno por ellos diagnosticado, analizando desde una clave cultural e histórico generacional, el modo en que las nuevas características del faccionalismo socialista son expresadas en los discursos y relatos de las distintas generaciones hasta el año 2015. Se pondrá atención a cómo la subjetividad militante otorga valoraciones y sentidos a las facciones, sus lógicas, sus códigos y su historia, para lo cual se han analizado testimonios orales de 24 militantes PS, de distintas edades, que son o han sido dirigentes faccionales partidarios en diferentes contextos, y que socializaron, siendo jóvenes, en distintos tramos del periodo 1973 - 2015. Tales testimonios fueron obtenidos mediante entrevistas realizadas entre los años 2012 y $2015 .^{5}$

Los principales hallazgos son:

- a) Los grupos internos del PS serían en menor proporción "corrientes" o "tendencias" políticas con diferencias ideológicas relativas a los programático, y en mayor sentido "agrupamientos" de orientación pragmática, funcionales a la organización del poder interno y la distribución de roles, cargos y candidaturas sujetas a elección ciudadana, lo que en la jerga militante actual se ha denominado "sectores" o "lotes".

- b) Existe una diferencia generacional en el modo en que se establece un vínculo subjetivo con la facción. Los militantes adultos socializados en dictadura narran las

\footnotetext{
${ }^{4}$ Ricardo Gamboa y Rodrigo Salcedo, "El faccionalismo en el partido socialista de Chile (1990 - 2006): Características y efectos políticos en sus procesos de toma de decisión”, Revista de Ciencia Política, volumen 29, número 3, Pontificia Universidad Católica de Chile Instituto de Ciencia Política, Santiago, 2009, 667692.

${ }^{5}$ Las entrevistas realizadas en 2012 - 2013, se enmarcaron en el proyecto Fondecyt posdoctoral número 3110075. Las entrevistas del 2015 corresponden a la ejecución del Fondecyt Iniciación ya citado.
} 
lógicas presentes como algo que entienden y conocen, pero que no les genera un compromiso identitario fuerte, diagnosticando en ellas una instrumentalidad que choca con ciertas valoraciones militantes adquiridas durante su juventud. En cambio, los militantes actuales de la Juventud Socialista JS (que ingresan entre el 2000 y 2015), establecen un mayor sentido de pertenencia y afecto al subgrupo, el que se asocia fundamentalmente a valoraciones relativas al estilo y la cultura organizacional, de igual modo que se produce una mayor valoración del involucramiento faccional y del conocimiento de las dinámicas y códigos que éste implica.

- c) Sin perjuicio de lo anterior, durante las coyunturas de nacimiento de una facción, ya sea por quiebres - realineamientos de viejas facciones o por vía de la emergencia de colectivos sectoriales que derivan en corrientes, se ha producido un mayor énfasis en distinciones político - programáticas que aquellas presentes en facciones ya consolidadas, y suele ocurrir que a medida que la facción se consolida o inserta en las estructuras de poder partidario, dichos énfasis van perdiendo la relevancia que tuvieron en un principio.

En función de exponer y contextualizar tales conclusiones, se ha organizado el artículo en tres partes. Un primer punto expondrá la triada conceptual que sostiene el problema planteado: generación, cultura política y faccionalismo. En segunda instancia se expondrá un breve relato orientador respecto a la evolución contemporánea del faccionalismo socialista entre 1973 y 2015. Por último, se realizará el análisis generacional del faccionalismo en dos grupos previamente identificados: militancia PS socializada como joven en dictadura y la juventud socialista actual.

\section{1.-Marco conceptual. Generación, cultura política y faccionalismo}

Brevemente, se expondrán las tres categorías fundamentales que recorren el presente artículo: generación, cultura política y faccionalismo partidista.

\section{1- Generaciones}

Un estudio generacional atiende al vínculo entre sujeto, posición en la estructura social y tiempo. Lo temporal, en este caso, no sólo implica el carácter "contemporáneo" de los sujetos analizados (compartir un tiempo histórico), sino también aquello que conecta a los "coetáneos" (que comparten un tiempo biográfico). Un autor clave para los enfoques generacionales es Karl Mannheim ${ }^{6}$, quien diferenciándose de lo sostenido por las tradiciones europeas del positivismo francés y el pensamiento histórico romántico alemán,

${ }^{6}$ Karl Mannheim, "El problema de las generaciones", Revista Española de Investigaciones Sociológicas, número 62, Madrid, 1993. 
propuso un abordaje del concepto "generación" que otorga centralidad al contexto sociohistórico presente durante la socialización del sujeto en su periodo juvenil. Mediante el concepto "estratificación de la vivencia", Mannheim sostuvo que lo vivido por los jóvenes constituye "primeras impresiones" que se configuran como "imagen natural del mundo", razón por la que todas las experiencias posteriores o tardías, se verían orientadas de acuerdo a aquella primera impresión, ya fuera como afirmación de ese estrato o como negación de aquel. Se produce, a su entender, una relación "dialéctica" en la vivencia, pues lo que se vive no se va acumulando sino que se enfrenta en los sentidos ya señalados: "el predominio de las primeras impresiones permanece vivo y determinante, aun cuando todo el decurso sucesivo de la vida no tenga que ser otro que el de una negación y una descomposición de la "imagen natural del mundo" recibida en la juventud". Para este autor, es la juventud también el momento en que el sujeto capta aquello que ha sido problematizado en la cultura, de modo que la socialización incorpora las tensiones relativas a lo que cambia y se conserva en sociedad, punto central de lo político. En el suceder de las generaciones, al cambiar el mundo, van cambiando los contextos de las experiencias primarias y sus referencias orientadoras, de modo que mientras los viejos se enfrentan continuamente a algo que permanece en ellos (plasmado en su conciencia como exterioridad vivida), los jóvenes tienen como referencia básica un mundo diferente al de los viejos. Tal distancia distingue a las generaciones entre sí, pues aunque sujetos presentes y de distintas edades compartan una posición social de contemporaneidad (como la militancia en el PS actual), los puntos de partida de cada "estratificación de la vivencia" serán diferentes.

En el estudio de las militancias, el abordaje del factor generacional se ha complementado con el estudio de las transformaciones en los partidos (cambios en sus tácticas, sus nociones doctrinarias y políticas de alianzas) a partir de la vivencia de determinados contextos por parte de los sujetos militantes. Lo anterior ha sido conceptualizado por la ciencia política como "aprendizaje político", y en el presente texto se vincula con el modo en que las vivencias generacionales inciden en las transformaciones del PS, particularmente las vivencias de la dictadura y la posdictadura. ${ }^{8}$

En definitiva, la pregunta que recorre el presente texto es por la marca generacional en las percepciones, interpretaciones y valoraciones relativas al faccionalismo, lo que se relaciona con la construcción cultural de la contemporaneidad militante socialista. ${ }^{9}$

\footnotetext{
${ }^{7}$ Mannheim, op.cit., 217.

${ }^{8}$ Ver: Nancy Bermeo, "Democracy and the Lessons of Dictatorship", Comparative Politics 24, 1992. Larry M. Bartels, Dimon Jackman, “A generational model of political learning”, Electoral Studies 33, 2014. Sobre el concepto "aprendizaje político" en el análisis de partidos chilenos, ver: Marcelo Mella, "Transición y democratización durante el gobierno de Patricio Aylwin (1990 - 1993): La estrategia de las cuerdas separadas", Revista Enfoques número 21, Santiago, Universidad Central, 2014.

${ }^{9}$ Entre algunos tratamientos contemporáneos del concepto de generación a partir de la obra de Mannheim: Víctor Muñoz Tamayo, Generaciones. Juventud universitaria e izquierdas políticas en Chile y México. Santiago, Lom, 2011. Carles Feixa y Carmen Leccardi, "El concepto de generación en las teorías sobre la juventud”, Última Década 43, CIDPA, Valparaíso, 2011. Felipe Ghiardo, “Generaciones y Juventud: una
} 


\section{2.- Cultura Política}

Sobre el concepto cultura política, vale indicar que las diferentes disciplinas y escuelas han desarrollado distintos temas y énfasis referidos a la conexión entre política y cultura. Por lo mismo, en los estudios de "cultura política" en América Latina es posible encontrar desde los que priorizan métodos cuantitativos en el estudio de las apreciaciones ciudadanas sobre el sistema político, sus actores e instituciones, hasta los que recurren a metodológicas cualitativas para explorar ámbitos que trascienden el ordenamiento institucional de la política, como es el caso de las configuraciones subjetivas, cotidianas e identitarias de la esfera pública. O desde los que se orientan por definiciones de un "deber ser" de "cultura política" en tanto cultura cívica moderna, hasta los que asumen el ámbito político cultural como una amplitud compleja y en constante mutación, redefinición y pugna. ${ }^{10}$

La polisemia del concepto, no niega, sin embargo, que el interés por el estudio de la cultura política tiene en América Latina un contexto en común durante las últimas décadas. Fenómenos como el término de las dictaduras militares, la emergencia del neoliberalismo globalizado, la crisis del marxismo y de los desarrollismos a fines del siglo XX, gatillaron cambios de paradigmas en torno a la configuración del campo de la política y el carácter de las actorías sociales en él. De algún modo, estos cambios y el rompimiento de los moldes de comprensión que en los contextos previos solían vincular mecánicamente condiciones estructurales con orientaciones y actorías políticas, obligan a acudir a la cultura en busca de la diversidad de elementos identitarios que inciden en las opciones, orientaciones, apuestas, sentidos y lógicas involucradas en la construcción de la esfera política. El presente artículo también debe ser entendido como parte de esta búsqueda y asumimos que perspectivas que han atendido al problema de las generaciones han sido también un componente destacado dentro de los análisis de cultura política y cultura política militante en América Latina. Como lo señalara Fabio López de la Roche: "Otra dimensión de los análisis de cultura política que introduce la aproximación histórica a su configuración y crecimiento, estaría relacionada con las distintas atmósferas generacionales, que se suceden en el desarrollo de la sensibilidad política colectiva de una nación o de una comunidad."11

El foco del presente estudio se encuentra en una especificidad del área de la cultura política que es el de las culturas militantes, es decir, nos abocaremos a los cruces entre cultura y política al interior de un partido, atendiendo a cómo el aspecto generacional incide en la producción de códigos, prácticas y sentidos de militancia. En esta búsqueda, se intentará dar cuenta de la producción de la identidad partidaria socialista y sus facciones en relación

Relectura desde Manheim y Ortega y Gasset", Última Década 20, Valparaíso, CIDPA, 2004. Víctor Muñoz Tamayo, "Juventud y política en Chile. Hacia un enfoque generacional", Última Década 35, Valparaíso, CIDPA, 2011. Manuel Canales, Felipe Ghiardo y Antonino Opazo, "Para un concepto de juventud", Pablo Cottet editor, “Juventudes. Metáforas del Chile Contemporáneo", Santiago, Ril, 2015.

${ }^{10}$ Un detalle y análisis sobre los contenidos, enfoques y metodologías de los estudios sobre cultura política en América Latina en: Fabio López de la Roche, "Aproximaciones al concepto de cultura política". Convergencia número 22, Universidad Autónoma del Estado de México, Facultad de Ciencias Políticas, Toluca, México, 2000, 393 - 424.

${ }^{11}$ De la Roche, op.cit., 98. 
a los universos discursivos, los valores, las formas y lógicas de organización y toma de decisiones, los relatos sobre la historia militante, las imágenes de "nosotros" y "otros"12, así como el modo en que se entiende la relación entre lo social y la política ${ }^{13}$.

\section{3.- Fracciones, facciones, tendencias y corrientes}

En el marco de un estudio de subjetividad política debe haber un doble trabajo relativo a los conceptos: por un lado, presentar los instrumentos categoriales para el análisis en el marco de lo debatido en las ciencias sociales, y por otro, atender a las categorías que la propia cultura militante establece para dar cuenta de su realidad. Sobre el faccionalismo, es preciso aclarar que no hay una terminología consensuada y establecida en las ciencias sociales para definir las subdivisiones partidarias. Al respecto, el cientista político Giovani Sartori $^{14}$ sostiene que sus colegas de distintos países de Europa usan categorías como "corrientes", "tendencias", "facciones" y "fracciones" para referirse a cuestiones diferentes, razón por la que el mismo autor señala que la conceptualización que él propone no es una norma extendida. Dentro de la particular propuesta conceptual de Sartori, se opta por llamar "fracción" al fenómeno general de la subdivisión partidaria, distinguiendo en ese nivel entre las "tendencias" que sugieren conjuntos establecidos de actitudes que expresan diferenciaciones poco visibles, y las "facciones" que serían grupos específicos y con alta visibilidad dentro de un partido. En el plano subjetivo, la historia reciente del PS da cuenta de cambios en los modos de nombrar el fenómeno faccional. Por ejemplo, en el PS unificado antes del golpe y en el PS unificado con inmediata posterioridad a 1990 primaron términos como "corrientes" y "tendencias" para nombrar los subgrupos internos, los que tenían una visibilidad que cabía dentro de la definición que Sartori da a facción, mientras que durante la dictadura, cuando las fracturas del socialismo produjeron grupos autonomizados, se usó principalmente el término "fracción" o "facción" para nombrarlos. Palabras como "tendencia" y "corriente" han sido usadas por la militancia socialista para relevar diferencias políticas que se manifiestan en grupos organizados, cohesionados y visibles, pero durante la posdictadura fueron apareciendo nuevos términos que indicaban básicamente el hecho del agrupamiento de militantes para operar internamente, como ha ocurrido con los términos emergentes "sector" o "lote", este último, particularmente recurrente en la militancia más joven.

Para el periodo estudiado, junto con tratar la nomenclatura usada por los propios militantes, sus sentidos asociados y transformaciones históricas, se usará para el análisis el término "facción” según la propuesta de Sartori. En este último sentido, se coincide con Gamboa y

\footnotetext{
${ }^{12}$ En esa línea de estudio histórico - cultural de militancia, ver: Cristina Moyano, MAPU o la seducción del poder y la juventud, Santiago, Ediciones UAH, 2009.

13 Tal problemática Norbert Lechner la pone al centro de su comprensión del concepto "cultura política", al entenderla como expresión de "la producción y reproducción de las concepciones que elabora una sociedad acerca del campo de la política y, específicamente, de la "representación" de la política respecto a la sociedad." Norbert Lechner, "Cultura política y democratización", Norbert Lechner Obras escogidas, tomo 2, Santiago, Lom, 2007, 244.

${ }^{14}$ Giovanni Sartori, Partidos y sistemas de partidos, Madrid, Alianza, 2005.
} 
Salcedo $^{15}$ en que entre 1990 y el 2006 las subdivisiones del PS deben ser consideradas "facciones" según la definición de Sartori, dada su estabilidad, reconocimiento al interior del partido, organización interna (con reuniones periódicas) y coordinación tras objetivos comunes.

\section{2.- Antecedentes: la realidad faccional socialista $(1973-2015)$}

Durante el gobierno de Salvador Allende no hubo en el PS unidad de posturas en torno a la ruta a seguir para la construcción del socialismo, por lo que tal partido no mostró un compromiso cohesionado tras los lineamientos oficialistas orientados a una vía institucional. De hecho, importantes sectores se sintieron cercanos a las tesis que proponían fortalecer un "poder popular" que desbordara la institucionalidad y preparara las condiciones para asumir una vía insurreccional armada. ${ }^{16}$ Tras el golpe de Estado las divisiones persistieron en la clandestinidad y en el exilio, y aunque se logró construir una dirección en Chile con algunos miembros del Comité Central elegido en el Congreso de 1971, como el dirigente de los trabajadores portuarios Exequiel Ponce y el diputado y Secretario General de la Juventud Socialista Carlos Lorca, aparecieron grupos al interior del país que desconocieron a esa dirección, como la Coordinadora Nacional de Regionales CNR que conformó una dirección interior paralela a partir de estructuras orgánicas regionales (principalmente comités regionales Santiago Centro y Santiago Cordillera). Mientras tanto, Carlos Altamirano permanecía como Secretario General del PS en el exterior y era reconocido por la dirección interior, aunque ésta declaraba que la estructura exterior era subordinada a la dirección política ejercida desde Chile. ${ }^{17}$

Ponce, Lorca y la mayor parte de la primera dirección clandestina venían de un grupo que en los sesenta había construido una fuerte identidad con la cuestión militar, llegando a formar una facción militarista (la "Organa") y una sección chilena del Ejército de Liberación Nacional Boliviano ELN, las que se fusionaron conformando la corriente conocida como "los Elenos". ${ }^{18}$ No obstante este origen en el radicalismo guevarista, durante el gobierno de Allende los Elenos habían asumido la defensa de la conducción allendista y del fortalecimiento de la alianza con el PC, reclamando para ello un partido ordenado bajo las formas orgánicas y la disciplina interna propias de los partidos leninistas, las que fueron promovidas por la conducción de Lorca en la Juventud Socialista durante la UP.

\footnotetext{
${ }^{15}$ Gamboa y Salcedo, op.cit., 667-692.

${ }^{16}$ Joan Garcés, Allende y la experiencia chilena. Las armas de la política, Santiago de Chile, Hueders, 2013.

17 "La dirección política del Partido se ejerce desde Chile y a la dirección interior de la lucha revolucionaria se subordina el trabajo del Secretariado Exterior del Partido, encabezado por el Secretario General del Partido, Camarada Carlos Altamirano". En: Dirección PS interior, "Al calor de la lucha contra el fascismo, construir la fuerza dirigente del pueblo para asegurar la victoria”, marzo de 1974, www.socialismo-chileno.org

${ }^{18}$ Jorge Arrate y Eduardo Rojas, Memoria de la Izquierda Chilena, tomo dos, Javier Vergara editor, Santiago, 2003.
} 
Después del golpe, esta valoración de la disciplina partidaria se expresa en el documento que la dirección clandestina interior emite en el mes de marzo de 1974, conocido como "documento de marzo" ". En él se apuesta por un PS con organización leninista, el impulso de un sólo bloque de vanguardia obrera por vía de la alianza PS - PC, y un frente amplio antifascista con hegemonía proletaria, es decir, conducido por el mencionado eje socialista comunista. $^{20}$ En relación al histórico faccionalismo socialista, el Documento de Marzo propone combatirlo, pues considera que sólo un PS ordenado y homogéneo podría cumplir debidamente las tareas atribuidas a un partido obrero, más aun en los difíciles momentos de la clandestinidad:

Es indispensable transformar la actual organización en un Partido homogéneo, desarrollando la ideología proletaria, poco arraigada aún, introduciendo el marxismo-leninismo en la práctica concreta de los militantes, combatiendo sistemáticamente todas las desviaciones (...) El combate a muerte a los rezagos de actividad fraccional, es un compromiso que la dirección cumplirá sin vacilaciones (...)Las actuales condiciones represivas exigen practicar efectivamente el centralismo democrático, enfatizando hoy la centralización de la dirección política. ${ }^{21}$

Esta primera dirección clandestina fue detenida por la DINA y hecha desaparecer en 1975, pero dejó instaladas una serie de ideas fuerza relativas a la evaluación de la derrota y los caminos a seguir. En lo evaluativo hubo dos críticas, una a las líneas más moderadas y otra a las del izquierdismo radical durante la UP. Sobre las primeras se diagnosticó una magnificación de las posibilidades de la vía pacífica (crítica al PC), las que habrían obviado el carácter de clases de la institucionalidad burguesa sin producir claridad en las masas sobre el enfrentamiento social y la violencia revolucionaria. Sobre las segundas, se planteaba que un extremismo infantil pequeño burgués (crítica al MIR y a posiciones dentro del propio PS) se limitó a la verborrea insurreccionalista, sin diferenciar los enemigos principales del proyecto socialista, desechando cualquier acuerdo táctico con representantes sociopolíticos de las capas medias, y reduciendo la revolución y el problema del poder a meras situaciones de enfrentamiento. En lo referente al rol partidario, se sostenía que el PS no había podido establecer una línea única, creciendo en él desviacionismos de izquierda que dispersaron las fuerzas sociales, debilitaron al gobierno e imposibilitaron una dirección obrera de un proceso que articulara el poder del gobierno con la fuerza de un movimiento de masas. Sobre los caminos a seguir, se instaló la idea de una alianza PS -PC como vanguardia proletaria de un frente amplio antifascista que debía combatir no sólo un esfuerzo restaurador de posiciones perdidas por la gran burguesía, sino una transformación mayor orientada a superexplotar la mano de obra, estimular la inversión extranjera, favorecer la libre competencia, rebajar los aranceles a las importaciones, y fortalecer la concentración de la propiedad y la producción. De hecho, se sostenía que la concentración de la riqueza haría factible una alianza amplia con los sectores más afectados

\footnotetext{
${ }^{19}$ Dirección PS interior, op.cit.

${ }^{20}$ Dirección PS interior, ibid.

${ }^{21}$ Dirección PS interior, ibid.
} 
de la pequeña burguesía y la burguesía no monopólica, lo que implicaba asumir que la revolución socialista no sería el objetivo de esta etapa de lucha, sino la restauración y ampliación de las conquistas sociales de los trabajadores con miras a una "democracia popular".

Si bien los lineamientos del Documento de Marzo llegaron a ser hegemónicos en la militancia clandestina interior, durante todo el periodo post golpe y en la segunda mitad de los años setenta surgieron direcciones paralelas y opuestas a sus orientaciones: la ya citada CNR que se distinguía por cierta presencia trotskista ${ }^{22}$ y una evaluación de la derrota como costo de las políticas "reformistas" promovidas por el PC (por lo que proponía un distanciamiento de este partido) ${ }^{23}$; la llamada "Dirección de Consenso" que agrupaba a una facción que había sido expulsada de la Juventud Socialista en 1972 (los "militantes rojos"); el Movimiento Revolucionario Manuel Rodríguez (MR2) también llamado "La Chispa" que era una corriente guevarista de socialistas ex miristas ${ }^{24}$; por nombrar algunas de las facciones más importantes. ${ }^{25}$ Mientras tanto en el exilio, militantes influenciados por la izquierda de Europa occidental impulsaron un proceso que se denominó "renovación socialista", que buscaba dar lugar a una "concepción coherente entre las relaciones entre socialismo y democracia" 26 , cuestionando las concepciones leninistas en torno a ello, y promoviendo un distanciamiento político ideológico con los socialismos de Europa del Este. La emergencia de este proceso reflexivo, sumado a una historia de diferencias previas y disputas en torno a la legitimidad de las direcciones, ${ }^{27}$ significó que a fines de la década del 70 el PS en el exilio apareciera notoriamente dividido en dos bloques. Por un lado, el liderado por Carlos Altamirano, con redes en Europa Occidental y todo el revisionismo doctrinario y político de la "renovación socialista". Por otro, el liderado por Clodomiro Almeyda, con centro de operaciones en Berlín oriental (por tanto, sin mayores cuestionamientos a los socialismos reales), que proponía una alianza estratégica con el PC y formas leninistas de organización partidista, es decir, contenidos doctrinarios y políticos coincidentes con la dirección interior heredera del Documento de Marzo.

\footnotetext{
${ }^{22}$ El trotskismo era un elemento constante de la vida faccional del PS. Durante los años sesenta, grupos trostskistas habían derivado al MIR, pero varios de esos cuadros retornaron al PS luego de rupturas al interior de la organización liderada por Miguel Enríquez. Sobre esto último: Eugenia Palieraki, "iLa revolución ya viene! El MIR chileno en los años sesenta”, Santiago, LOM, 2014.

${ }^{23}$ Ricardo Yocelevzky, "El partido socialista de Chile bajo la dictadura militar", Foro internacional, volumen 27, número 1, Ciudad de México, El Colegio de México, 1986.

${ }^{24}$ Palieraki, op. cit.

${ }^{25}$ Mauricio Rojas, "La evolución del Partido Socialista de Chile durante la primera parte de la dictadura (1973 - 1979)”. Divergencia, número 5, Santiago, Taller de Historia Política, 2014, 9 - 34.

${ }^{26}$ En: Informe de Carlos Altamirano al Pleno Socialista conocido como de "Argel" en 1978 (nombre destinado a engañar a los servicios de la inteligencia chilena, pues en realidad se realizó en Alemania Oriental). Allí el Secretario General del PS en el exterior esboza ideas de lo que luego se conocerá como "renovación socialista". En Arrate, op. Cit., 286.

${ }^{27}$ Habían surgido una serie de desencuentros producto de que la dirección interior estimaba que la dirección exterior de Altamirano se manifestaba de modo ambiguo respecto a otorgarle total legitimidad. Uno de los más recordados episodios que reforzaba esta idea fue cuando la dirección de Altamirano, junto con convocar a la dirección interior al pleno de la Habana en 1975, convocó también a quienes disputaban la legitimidad de su conducción: los representantes de la CNR.
} 
La tensión se fue haciendo insostenible y en el Tercer Pleno Clandestino del PS realizado en Chile durante 1979 se resolvió la expulsión de Carlos Altamirano, acusándosele de tener posiciones de derecha y de querer dividir al movimiento popular al promover una salida a la dictadura con la Democracia Cristiana pero excluyendo al PC. ${ }^{28}$ Altamirano, por su parte, lejos de aceptar la resolución optó por llamar a un Congreso del PS, el número XXIV, con lo que se materializaba la división. Mientras el PS dirigido por Altamirano concitó en el exterior un importante apoyo que le permitía disputar influencia frente al almeydismo, el grueso de la militancia interior apoyó al "PS Almeyda" en tanto expresión orgánica de la política heredera del Documento de Marzo.

Durante los años ochenta el PS liderado por Almeyda mantuvo a este último como Secretario General, mientras que Altamirano cedió la dirigencia de su facción a otros líderes cuyos apellidos sirvieron para nombrar al PS de la renovación: "Arrate", "Núñez", "Briones" (también se le llamó PS XXIV Congreso). A partir de su nacimiento, el PS de la renovación formó una alianza política con los dos partidos MAPU $^{29}$ y con la Izquierda Cristiana IC, que se llamó la "Convergencia Socialista", organización que llegó a formalizar un secretariado con representantes de los partidos en el interior del país durante 1982. En 1983, un grupo de militantes de la Democracia Cristiana DC, otros identificados con una derecha no pinochetista, y otros de identidad PS y PR (Partido Radical), firmaron el "Manifiesto Democrático" que proponía un "acuerdo nacional" para el retorno de la democracia. De los firmantes de este manifiesto surgió luego la Alianza Democrática (AD), coalición que reunió a la DC, al Partido Liberal — con orientación de derecha—, al PR y al PS de la renovación liderado por Núñez. La AD intentó desarrollar un diálogo con el régimen por vía del ministro del Interior Sergio Onofre Jarpa, discutiendo con él puntos como el reconocimiento de los partidos, la represión, el exilio y otros, hasta que en septiembre de 1983 tal diálogo fue desechado por el propio Pinochet. ${ }^{30}$ Paralelamente, el PC, el PS Almeyda y el Movimiento de Izquierda Revolucionaria MIR, como una forma de contrarrestar la opción dialogante y moderada de la $\mathrm{AD}$, formaron el Movimiento Democrático Popular (MDP) que se proponía intensificar la movilización rupturista como modo de provocar el derrocamiento del gobierno. Para ese entonces, la política del PS Almeyda con respecto a la dictadura era denominada "lucha de masas rupturista con perspectiva insurreccional" ${ }^{31}$ (refrendada en la versión almeydista de XXIV congreso en $1985^{32}$ ), lo que suponía una radicalidad que acercaba posiciones con el PC y su "Política de

\footnotetext{
${ }^{28}$ Edison Ortiz, El socialismo chileno de Allende a Bachelet. (1973 - 2005), Santiago, Alerce Talleres Gráficos, 2007.

${ }^{29}$ Movimiento de Acción Popular Unitario formado en 1969 de una escisión de la Democracia Cristiana DC. En 1973, en un contexto de tensiones al interior de la UP, el MAPU se dividió en dos partidos.
}

${ }^{30}$ A estas jornadas de diálogo no asistieron representantes socialistas de la AD que rechazaron sentarse a la mesa con un gobierno que había diezmado a su partido. Arrate, op.cit.

${ }^{31}$ Muñoz, op.cit.

32 Las resoluciones del XXIV congreso almeydista ratifican la línea denominada: "Lucha unitaria y democrática de masas, de carácter rupturista y con perspectiva insurreccional", que incluía la validez de "todas las formas de lucha que contribuyan a consolidar y potenciar el movimiento de masas". La idea era promover el derrocamiento de la dictadura por vía de la movilización de masas y en el marco de una unidad 
Rebelión Popular de Masas". Durante 1983, con parte de su conformación adscrita a la AD, surgía el Bloque Socialista que reunía al MAPU, la IC y el PS de la renovación. Mientras tanto, en el PS Almeyda, los dirigentes Julio Stuardo y Akin Soto firmaron el Manifiesto Democrático y luego entraron al Bloque Socialista, protagonizando un quiebre con el almeydismo que potenció al ala renovada del socialismo en Chile. ${ }^{33} \mathrm{Al}$ año siguiente, en 1984, un grupo que proponía acentuar y definir un lineamiento insurreccional armado contra la dictadura, rompió con la fracción almeydista (pues consideraba que el partido no le daba forma concreta a su declarada opción insurreccional) y fundó un nuevo partido que se conoció como "Dirección Colectiva" o "Socialistas Comandantes" 34 . En general, en esos años proliferaron los grupos y pequeños partidos de identidad socialista, ya fuesen radicales o moderados, al punto que en la década de 1980 llegaron a existir cerca de una veintena de facciones orgánicas ${ }^{35}$. Entre otros grupos que podemos mencionar hay partidos socialistas insertos en la Alianza Democrática o cercanos a ella como el "PS Histórico"36, la reconstruida Unión Socialista Popular USOPO ${ }^{37}$, y el "PS Mandujano",38; así como agrupaciones de izquierda radical con diagnóstico similar al de "los comandantes", como el "PS Salvador Allende",39.

En el año 1987 el PS Almeyda fue acercando posiciones con los otros partidos socialistas sentándose las bases para una unidad materializada en 1990, con lo que el PS unificado se transformó en conglomerado oficialista de la ya gobernante Concertación de Partidos por la Democracia. En esta unidad convergieron los diversos PS, el grueso de la IC, sectores del MAPU, ex-comunistas y ex-miristas. Las facciones pre existentes permanecieron mientras otras nuevas emergieron. En el otrora almeydismo, a un sector más proclive a insertarse en el nuevo gobierno buscando acuerdos en pro de la gobernabilidad y más conectado con las ideas fuerza de la renovación se le denomino Tercerismo; mientras otro grupo más crítico

opositora con base en un "gran acuerdo democrático". No obstante esto último, se estimaba que lo prioritario para esa unidad amplia era resguardar la unidad de la izquierda radicada en el MDP. Lo militar era subordinado a la lucha de masas y se relacionaba con dos aspectos: "el desarrollo de la autodefensa de las masas y la aplicación de una política hacia las fuerzas armadas, orientada a debilitarlas y provocar su colapso". Las citas textuales en: Resoluciones del 24 congreso del Partido Socialista de Chile. Agosto 1985.

33 Sobre la trayectoria en Chile del socialismo renovado: Joaquín Fernández, Álvaro Góngora, Patricia Arancibia, "Ricardo Núñez. Trayectoria de un socialista de nuestros tiempos”, Santiago, Universidad Finis Terrae, 2013.

${ }^{34}$ El proceso de quiebre y salida de los "comandantes" es fechado entre fines de 1984 y principio de 1985, durante la convocatoria al XXIV congreso. El principal líder del PS de los comandantes fue Eduardo Gutiérrez. Ortiz, op.cit.

${ }^{35}$ Ortiz, Ibid.

${ }^{36}$ Cuyo secretario general fue Juan Gutiérrez.

37 Facción autónoma que fundó Raúl Ampuero en 1967, se disuelve después del golpe de Estado y se reconstruye en la década de 1980 con la dirección de Ramón Silva Ulloa.

${ }^{38}$ Cuyo Secretario General era Manuel Mandujano.

${ }^{39}$ Tiene su origen en una corriente del exilio socialista, en Bélgica (Bruselas), la que es expulsada del PS Almeyda. Al igual que el PS Dirección Colectiva, el "PS Salvador Allende" apostaba por definir y fortalecer el aspecto insurreccional de la lucha contra la dictadura. Su mayor dirigente es Robinson Pérez. Ver: Eduardo Gutiérrez, Ciudades en las sombras (una historia no oficial del Partido Socialista de Chile), Santiago, Editores Asociados, 2010. 
de la conducción política y económica de la transición en posdictadura se consolido como la corriente Nueva Izquierda. ${ }^{40}$ En la Renovación se dieron divisiones entre sensibilidades distintas representadas en los dos liderazgos más fuertes, Arrate y Núñez, llegándose a hablar de un "arratismo" y un "nuñismo". A juicio de algunos analistas, las diferencias eran principalmente de adscripción político cultural, ya que mientras el primero se manifestaba más cercano a la tradición del socialismo chileno el segundo optaba por conectarse identitariamente con una social democracia pragmática europea. ${ }^{41}$ A esta configuración de facciones le siguieron quiebres y nuevas emergencias de subdivisiones como:

- Colectivo de identidad socialista: Surge de un grupo de la Nueva Izquierda denominado "Generacional", dada su adscripción identitaria a los movimientos juveniles de los años ochenta. En 1997 este grupo difiere de la conducción partidista de Camilo Escalona y funda el "Colectivo" cuyo discurso se orienta a la recuperación de la identidad de izquierda y transformadora en el partido. Ha tenido como líderes a los alcaldes Sadi Melo (El Bosque) y Julio Palestro (San Miguel).

- Megatendencia o Renovación: agrupación conformada en 1995 reuniendo al arratismo y el nuñismo.

- Nuevo Socialismo: grupo formado el 2005 por Gonzalo Martner y Arturo Barrios tras la crisis que le significó al primero la salida de la presidencia del partido. Discursivamente reivindican una mayor ruptura con el modelo institucional y económico.

- Grandes Alamedas, escisión de la Megatendencia liderada por Isabel Allende en donde confluye la corriente "Nuevo Socialismo". Su orientación está muy definida por la oposición a la conducción, los estilos y la influencia ejercida por Camilo Escalona y la Nueva Izquierda.

- "Nuestra Revolución", sector opositor a la hegemonía de Nueva Izquierda y sus aliados circunstanciales, con un discurso que reivindica estilos políticos no autoritarios. Lo lideran los diputados Marcelo Díaz y Alfonso de Urresti. Confluyeron en él cuadros que venían de Grandes Alamedas (como Arturo Barrios) y de nueva izquierda (el propio Marcelo Díaz).

\footnotetext{
${ }^{40} \mathrm{El}$ tercerismo fue conducido por cuadros que organizaron al PS desde la segunda mitad de los años 70 como Ricardo Solari, Jaime Pérez de Arce y Germán Correa, mientras Nueva Izquierda fue conducida por Camilo Escalona, ex líder estudiantil secundario durante la UP que ingresó clandestino a Chile en 1982 junto a un grupo de militantes del almeydismo. A nivel social, el tercerismo contó con buena parte de los ex cuadros universitarios y la Nueva Izquierda fue particularmente fuerte a nivel poblacional. Sobre el trabajo orgánico de Camilo Escalona en su regreso a Chile ver: Álvaro Peralta y Enzo Pistacchio, "Duro de matar", Santiago, Zig-Zag, 2014.

${ }^{41}$ Gamboa y Salcedo, op. Cit., 667-692.
} 
- Frente Allendista, corriente que emerge el 2010, se define como anticapitalista y crítica de lo que llaman un acomodo del PS en el orden neo liberal, siendo también críticos del proceso de Renovación Socialista.

Durante la posdictadura la dinámica interna del PS fue cambiando, y la vieja estructura con base en núcleos de militancia fue dando paso a una matriz orgánica en donde las unidades más básicas suelen ser los comunales (denominación de referencia territorial o funcional). Lo anterior reforzó la tendencia que establecía que la militancia cotidiana se realizaba fundamentalmente desde la referencia faccional, y desde ahí se interactuaba con las diferentes esferas del partido y la juventud. Por otro lado, tal como lo sostienen Gamboa y Salcedo $^{42}$, las características propias de la realidad electoral, es decir, el que el PS pertenezca a una coalición de varios partidos que compite dentro de un sistema electoral binominal, hace que el faccionalismo se vea incentivado, puesto que este partido tiene acceso a un número limitado de cupos para una elección parlamentaria, y la definición de tales cupos se relaciona con el peso interno de cada facción.

Hoy en día, tanto las elecciones internas del PS como las conferencias y congresos partidarios son, en tanto momentos en que se establecen cargos y emiten pronunciamientos, instancias claves para la reproducción de la actual lógica de facciones. Ahí cada sector establece sus alianzas, emergen quiebres y, eventualmente, nuevas facciones. Son los momentos en que se materializa la lealtad con la corriente, y en donde cuadros con capacidad de movilizar apoyos hacen sentir su influencia, primero, engrosando los padrones de militancia con sus leales, y en segundo término, movilizando a esos leales a participar y votar. Entre los aspectos que determinan las lealtades están las historias compartidas, los caudillismos locales, y un no menor clientelismo expresado particularmente en redes de distribución de empleos en organismos de gobierno nacional, provincial o municipal; o directamente por vía de cargos de confianza política en el sistema público cuando éste se ha encontrado bajo la administración de la coalición a la que pertenece el PS. Las facciones cuentan con una organización tácita, pues aunque los estatutos partidarios asumen la existencia de "corrientes de opinión", precisan que ellas deben ser "de existencia transitoria y sin disciplina propia" ". Por ello, la dinámica de facciones y entre facciones se corresponde con lógicas y códigos de características consuetudinarias y no contenidas en la normativa partidista. Toda facción establece reuniones más o menos esporádicas, restringidas o ampliadas, y tanto en el Partido como en la Juventud JS cuentan con coordinadores que son los que organizan el proceder interno de los subgrupos, convocan a las reuniones e interlocutan en su representación. ${ }^{44}$

\footnotetext{
${ }^{42}$ Gamboa y Salcedo, op. Cit., 683.

${ }^{43}$ PÁRRAFO 4 - Artículo 51 de los estatutos del PS: "En el Partido no podrán existir fracciones, sino sólo corrientes de opinión con existencia transitoria y sin disciplina propia". Estatutos del Partido Socialista de Chile, Noviembre del 2003, www.pschile.cl

${ }^{44}$ La caracterización que se hace en este párrafo se realizó a partir del trabajo de campo de la propia investigación. En ello se profundizará y citarán testimonios.
} 
Tras la llegada de Michelle Bachelet al poder el 2014 y el proceso de elecciones internas del socialismo en el año 2015, se produjeron nuevos reordenamientos de fuerzas y divisiones, emergiendo otras corrientes (aunque todavía es muy pronto para conocer su estabilidad en el tiempo, más allá de la coyuntura electoral) ${ }^{45}$ como Tercera Vía donde convergieron algunas dirigencias salidas del Colectivo de Identidad Socialista bajo el liderazgo de Gonzalo Martner.

\section{3.- Generaciones y faccionalismo. Percepciones, lógicas, identidad y sentidos}

El análisis se hará a partir de la identificación de dos generaciones. Por una parte, aquellos que socializaron en el PS siendo jóvenes durante la dictadura. Por otro, los jóvenes socialistas del presente.

\section{1- La generación socializada en dictadura}

Los socialistas que comenzaron a militar siendo jóvenes durante la dictadura, entienden el mapa actual de las corrientes de acuerdo a lo que ellos conocieron en el momento de su socialización, estableciendo comparaciones entre ese pasado y el presente. De tal modo, su percepción en torno a los cambios en las prácticas, sentidos y lógicas de la cultura militante, se construye a partir del establecimiento de una relación dialéctica entre las nuevas vivencias de la posdictadura y aquellas del pasado dictatorial vividas durante la socialización militante juvenil, emergiendo una subjetividad de características generacionales. Si bien estos militantes siguen otorgando a su identidad faccional y a las identidades faccionales del resto algún tipo de fundamento, la mayor parte de las veces las describen como cuestiones muy distintas a las que estaban en la base de las distinciones entre corrientes durante los años de la dictadura e inicios de la transición. Esta percepción, que es mayoritaria y tranversal en las corrientes, tiende a comprender el fenómeno actual de las facciones como una cuestión que, aun cuando nace como expresión de diferencias políticas y estratégicas asociadas a grupos que compartían trayectorias, amistades y lealtades; fueron mutando al punto de que, si bien mantienen las lealtades e identidades con base en las trayectorias en común, pierden la especificidad política, ideológica y estratégica que tuvieron en un principio. Por ello, los testimonios sostienen mayoritariamente que las facciones existen principalmente como sustrato de lógicas de distribución y acceso a instancias de poder, es decir, como sistema que organiza la pugna al interior del partido por el acceso a cargos, ya se trate de puestos al interior de la estructura partidaria (cargos directivos, representaciones locales y regionales), de acceso a candidaturas sujetas a aprobación electoral (alcaldías, concejalías, diputaciones, senadurías, etc ) o de posiciones en instancias públicas dependientes del poder político (desde gabinetes ministeriales y dirección de servicios, hasta una infinidad de cargos de confianza política en

\footnotetext{
${ }^{45}$ Para el presente de la JS hay que considerar una serie de corrientes que se enmarcan en colectivos de militancia universitaria que pueden permanecer como expresión estrictamente estudiantil o trascender y emerger como nuevas corrientes al interior del partido, como el caso del grupo "Izquierda Socialista".
} 
el sistema público). Desde estas perspectivas, y en el tema específico de las diferencias entre las facciones, ocurriría que "la política" en tanto pugna programática e ideológica respecto a la construcción del orden deseado, sería mucho menos definitoria que "la política" en tanto distribución y operatividad del poder. Es decir, la tendencia sería que los deslindes se definen más por la instrumentalidad que por la ideología, más por los intereses de grupos e individuos tras cuotas de poder que por énfasis diferentes en las ideas relativas a la "buena sociedad" a construir. No obstante lo anterior, los militantes mantienen la idea de que su accionar individual y colectivo como socialistas sigue siendo fuertemente motivado por orientaciones político programáticas, pero aclaran que ello no se presenta como diferenciación de corrientes, ya sea porque habría un consenso socialista amplio en estos puntos o porque ese tipo de diferenciaciones son transversales y corren por un camino totalmente diferente al de la definición de subgrupos en el partido.

Yo creo que en algún minuto había una idea de agruparse en torno a ideas, a proyectos, pero al final fue perdiendo un poco sentido. Son lógicas de poder, a veces hay historias que unen más a unos que a otros. (Jaime Fuentealba- Colectivo de Identidad Socialista). ${ }^{46}$

Estas tendencias empezaron a perfilarse antes del 90, entonces, yo creo que nacieron más bien al calor de los debates que se generaron respecto a cómo concebir la transición, la salida de la dictadura y ese tipo de cosas. Se constituyó en el entorno, efectivamente, visiones, matices, distintas opiniones políticas sobre temas substantivos, pero después, efectivamente, se fueron perdiendo. (...)Yo creo que hoy día tienen que ver con las lealtades que se construyeron en todo este tiempo (previo) y en torno a las personas que siguen siendo activas y teniendo roles en el PS (...). Se mantienen las lealtades antiguas (...) pero me costaría mucho poder explicártelo en función de la realidad política actual. Yo creo que la política y lo programático dejaron de pesar hace mucho tiempo. (Jaime Perez de Arce- Tercerismo).

Yo creo que prácticamente todos los sectores internos del PS no tienen ninguna diferencia política muy fundamental, ni una, ni estructural ni ideológica. (...) Podríamos decir: los socialistas que están por más Estado o menos Estado, o por los que están por avanzar más rápido o más lento; yo creo que esas diferencias, que las hay, son transversales. (...) (Las facciones) son fundamentalmente grupos de poder, articulados todos más o menos de la misma manera, es decir, a partir de una determinada experiencia histórica, afinidades. (...)No responden a diferencias políticas ni para qué decir ideológicas, son sólo lógicas de poder que tienen que ver con cómo quedamos en la "distribución del animal", o sea los cargos públicos, las candidaturas en el espacio público, los cargos de Gobierno, etc. (Gonzalo Durán- Colectivo de Identidad Socialista).

\footnotetext{
${ }^{46}$ Se señala la facción de pertenencia de acuerdo al año en que se realizó la entrevista. Ver anexo.
} 
En esa época (dictadura e inicio de la transición) eran corrientes de pensamiento, o sea eran más que estructuras de poder, había debates, y era una discusión sobre estrategia política. (...)Lo de hoy no tiene nada que ver con lo del pasado. Hoy día son identidades, grupos de poder, que disputan espacios de poder y que mantienen las viejas identidades del pasado, pero no tiene esto que ver con debate ni discusión entre las tendencias, no existe eso. (Ricardo Solari- Tercerismo).

Se mantiene hasta mediados de los 90, una cierta lógica como de izquierdas y derechas dentro del PS o las corrientes, pero yo creo que llega un momento finalmente, los últimos cinco, ocho años, yo creo, que no hay ningún deslinde ideológico, son corrientes que quedaron constituidas por el momento histórico, por relaciones amicales, por socializaciones distintas. (Ernesto Águila. Tercerismo).

Las corrientes de opinión se han transformado muchas veces en grupos de poder, en donde las diferencias ideológicas no son tan pronunciadas como las que existían anteriormente. Yo creo que en el PS hay relativo consenso, un consenso muy amplio, respecto de lo que representa hoy día el socialismo y cómo se debe construir una alternativa política en el futuro. (Álvaro Elizalde- Tercerismo).

Cuando desde las corrientes se mencionan factores distintivos de la identidad, lo que más aparece es lo relativo a estilos de militancia, como suele ser cierta disposición a los debates intracorrientes, o a determinados rasgos de la democracia o disciplina interna. Otro aspecto que se señala es la presencia de ciertas ideas fuerza orientadoras del quehacer político, como en el caso del Tercerismo, que se atribuye una permanente disposición dialogante conducente a la búsqueda de acuerdos entre los distintos sectores del partido, o la Nueva Izquierda, que se asigna un sentido de responsabilidad política, razonamiento político y valoración de las instituciones, lo que se asume como aprendizaje ${ }^{47}$ o lección histórica del criticado rol jugado por el PS antes del golpe de Estado. Hay quienes describen cierta identidad y discurso original en relación al subgrupo, el que mutaría con los años en el sentido de perder énfasis, de modo que es común la referencia en pasado para hablar de la identidad: "en un momento sostuvimos...", "en un principio nos asumimos...". En general, ocurre que mientras más reciente es el evento fundacional, más presente está en los discursos la diferenciación de estilos, motivacional, e incluso la diferenciación política programática y estratégica referida al presente militante. En esto último, la excepción es la corriente Nueva Izquierda, pues su antigüedad no merma un alto valor asignado a las características propias, lo que se corresponde con su marcada cohesión orgánica.

Hay diferencias de estilo; hay corrientes que son más uniformadas, en términos de su actuar, más jerarquizables. Yo diría que, en general, la Nueva Izquierda tiene un grado de ordenamiento interno más nítido que

\footnotetext{
${ }^{47}$ Sobre "aprendizaje político" marcado por experiencias dictatoriales, ver el texto ya citado de Nancy
} Bermeo. 
las otras tendencias. (...)Un elemento que yo rescato del sector al cual pertenezco, es básicamente la importancia de construir, de transformarse en un puente de entendimiento para construir mayoría. (Álvaro Elizalde Tercerismo)

Nosotros somos un sector que le ha dado al partido, a los gobiernos de la Concertación y ahora al gobierno de la Nueva Mayoría, responsabilidad política. (...) La responsabilidad política que no tuvo el PS hasta el 73. (...) El infantilismo de la política trae lo que ocurrió con el golpe. Los que vivimos la dictadura entendemos que la política tiene que ser con responsabilidad. (Carlos Moreno - Nueva Izquierda)

Nosotros, en algún momento, aducíamos que nuestro grupo tenía un estilo más democrático. (Gonzalo Durán -Colectivo de Identidad Socialista).

La militancia socialista es consciente de que la organización interna está marcada por la estructuración de subgrupos, y que la dinámica faccional determina la participación al punto de que sería sumamente difícil (o imposible) intentar militar sin adscribir a corrientes, sobre todo si se tienen ciertas pretensiones de acceder a lugares de poder. En las percepciones de esta generación, los cambios en los sentidos y lógicas faccionales no se asumen con entusiasmo, y se suele declarar que hay valores del compromiso militante que se han perdido, no obstante, el faccionalismo tendría una función: ser la matriz desde la cual se estructura el reparto y el acceso al poder, ya sea dentro de la estructura partidaria o en relación a los cargos de representación y gobierno. Los más optimistas consideran que esa instrumentalidad y función pragmática de las corrientes se sostiene en un gran consenso político, ideológico y estratégico, de modo que no implicaría una degradación de los sentidos políticos de la identidad socialista. Los más pesimistas, en cambio, consideran que tal instrumentalidad y centralidad del interés por la obtención de poder, sería expresión de un decaer de los ideales y sentidos relativos a la construcción de sociedad, es decir, implicaría una crisis de la política como imaginario ético y orientado a la buena sociedad, así como el predominio de malas prácticas que recurren a clientelismos para ganar elecciones y reproducir el poder de los agrupados en la facción. En momentos, los entrevistados dejaban de hablar de "corrientes" y ocupaban términos que daban mayor énfasis a la instrumentalidad de los subgrupos como es el caso de la palabra "lotes" para referirse a las facciones. Lo anterior, lejos de involucrar una valoración positiva, dejaba entrever, la mayor de las veces, cierto malestar o percepción de pérdida de horizontes político - valóricos, de vínculos con la sociedad, o de compromiso no mediado por la obtención de beneficios personales. En esta última critica, fue recurrente la reflexión en torno a cierta imbricación entre militancia y acceso a puestos de trabajo, o entre corrientes y redes de repartición de trabajos, cupos y cargos. Todo lo anterior nos habla de una generación militante bastante crítica de su propia entidad política, lo que se ve acentuado en el marco de un relato que sopesa el presente a la luz de las experiencias pasadas previas a la democracia iniciada en 1990. 
La militancia se ha ido atomizando tanto que necesariamente tienes que adscribir a una (facción) para militar. Militar en este sentido de militar, que no es mi sentido primario de militar, porque militar, para mí, tenía que ver con un frente social, tenía que ver con un frente de masas, tenía que ver con una acción de lo ciudadano, en algún sentido, y ahora no. (...) Ahora ser militantes es participar de una de estas corrientes y ascender en el Partido. (Arturo Barrios- "Nuestra Revolución”).

Después del proceso de unidad deja de existir el militante y empieza a existir el afiliado, yo hago la distinción. Para mí el militante político es un sujeto que tiene la convicción de dos cosas, primero, hay un cierto proyecto político que orienta al militante y que desaparece, no hay socialismo, no hay nada de eso, nada, sólo el gobierno, el programa del gobierno; y segundo, el militante también siente que su participación, su actividad militante, ya sea por la vía del trabajo político, del trabajo orgánico, tiene un peso, tiene un peso decisorio, esos dos elementos dejan de existir rápidamente. Por decir el caso, un asesor en un ministerio, pesa más que un miembro del Comité Central, dentro del partido, porque ese asesor en primer lugar tiene pegas, da la posibilidad de trabajo, de consultoría, de asesoría. (...) De alguna manera fortalecías la vida tendencial por la vía del empleo, ya sea por la vía de las ONG para el Estado o directamente en el Estado (Enrique Acosta - Renovación).

Hasta el año 2000, más o menos, un poco antes, las facciones tenían un concepto dentro del PS, corrientes de opinión con una visión bien notoria, donde se hablaba y conversaba de política. (...)El tema de la política comenzó en algunos aspectos a burocratizarse y sacar el tema territorial, que es tan importante: el llegar a la gente. Y eso ha hecho que desde el año 2000, un poco antes, los sectores son prácticamente un sector de poder, no de política, que es una diferencia muy grande. (Carlos MorenoNueva Izquierda).

Yo pertenezco a un grupo en virtud de un conjunto de factores históricos, afectivos, relacionales $\mathrm{y}$, me atrevería a agregar, también como de subsistencia, porque los grupos de poder son los que te permiten asegurar de que vas a ser candidato y no te van a faenar. (...)Hay un gallo que adhiere a un sector, que hay gente que lo sigue, todos motivados por alguna expectativa de poder o privilegio, para decirlo de alguna manera brutal, y esos son los que, por un lado, tratan de cooptar a la mayor cantidad de militantes que voten por su lista cuando hay elecciones internas o, que es otra fuente de votación, meten a más gente al padrón (...) Y hay otros más "cara de raja" que van a la Junta de Vecinos y ofrecen no sé qué y meten a los dirigentes, y así tienen bolsones de votación, o meten a los funcionarios municipales en el Partido. Todo esto es un mecanismo de reproducción. (...)Yo he sido Concejal, miembro de la Comisión Política del Partido, pero no me importa la vida interna del Partido, no me interesa y me desagrada. (Gonzalo Durán- Colectivo de Identidad Socialista) 


\section{2.- La JS del siglo XXI}

Los jóvenes entrevistados para la presente investigación se socializaron como militantes entre la década del 2000 y el 2010, por tanto, el partido y la juventud partidaria que conocieron ya estaban organizados en torno a un faccionalismo con las características propias que éste adoptó en la posdictadura. Para ellos, las facciones al interior del partido, que suelen llamar "lotes", son una realidad permanente que inunda todos los aspectos de la cotidianidad. En general, se entiende que el militante juvenil se muestra públicamente como parte de un lote cuando realiza una acción en beneficio del subgrupo, sin embargo, el propio hecho de insertarse en el partido y vincularse con determinadas personas y colectivos que orientan su socialización, supone la inserción en dinámicas faccionales. Por lo mismo, muchos comienzan a militar en la JS sin tener claro cómo operan los subgrupos, sin establecer un nexo identitario con estos o sin plena conciencia de su posición al respecto, hasta que la etiqueta faccional emerge y se vuelve evidente. Esta última situación, muy común en el inicio de la militancia juvenil, la describen como "estar loteado sin saberlo".

Salvo los que tienen más experiencia o son un poco más vivos en términos de saber que el ingreso a un lote significa determinadas cosas, determinados apoyos, yo diría que el resto se junta con gente y de repente aparece con la etiqueta del lote. (Sebastián Rivera - Renovación)

Yo antes iba a reuniones, actividades, convocatorias, etc., pero, claro, yo iba porque toda la gente que estaba ahí, todas las personas que yo conocía, que eran mis amigos, al final eran todos de la misma corriente, y que yo al final terminé adscribiendo. (Karina Delfino- Nueva Izquierda)

No tení otra opción que meterte a uno de los lotes, porque toda la política interna se hace a través de los lotes. Uno llega como militante puro y sincero $^{48}$ a la sede del partido socialista a inscribir su ficha, lo primero es que desde el portero, hasta el secretario de organización que te pasa la ficha, hasta el que pasó al lado tuyo, va a tratar de meterte a su tendencia. Si tú te quisierai rebelar y no ser parte de ninguna tendencia la verdad es que no tienes mucho espacio para hacer participación política porque uno no se entera de las cosas que pasan en el partido si no participa en alguna de las tendencias. (Víctor Díaz- Renovación)

Hay muchos que ingresan a una tendencia, sin saber que es una tendencia, y después en el camino de la militancia se van dando cuenta que con ese grupo que comparten tiene un determinado nombre, tiene un determinado líder y que persigue determinadas ideas. (Daniel MeloColectivo de Identidad Socialista)

${ }^{48}$ Referencia al Himno del Partido Socialista Chileno: "Militantes puros y sinceros, prometamos jamás desertar...”. 
En la JS, la facción es el espacio básico de la militancia y, desde la relación entre facciones, opera el funcionamiento orgánico. Si bien hay "lotes" más organizados que otros, la práctica de tener reuniones periódicas es transversal, del mismo modo que el nombrar como coordinadores juveniles de facción a las más altas jerarquías al interior del partido, la JS, y sus respectivos comunales. En esto último se debe considerar que los estatutos partidarios no establecen una absoluta separación orgánica entre el Partido y la Juventud, lo que se expresa en cuestiones como que el presidente de la JS accede a ser miembro de la Comisión Política del Partido, la JS designa cinco miembros de su Comité Central para que participen en el Comité Central del Partido, y los presidentes regionales y comunales de la JS participan en las direcciones regionales y comunales del PS. ${ }^{49}$ Es importante que los códigos relativos a los liderazgos faccionales sean conocidos por la militancia, porque si bien no hay formalizacíon de los roles de "coordinador de sector", sí existe una cultura política que establece lo que es correcto e incorrecto, lo legítimo o agraviante en el establecimiento de las interlocuciones entre subgrupos. Todo ello es parte de la denominada "interna", aquel conjunto de prácticas y lógicas que articulan la vida partidaria y que adquieren un ritmo particularmente intenso en las coyunturas electorales.

Todos los sectores tienen sus coordinadores nacionales. (...) No está formalizado, está dentro de las informalidades. Pero por ejemplo ahora, nosotros estamos en el proceso de elecciones, uno conversa con quienes van a llevar la negociación por los sectores, obvio. (Cesar ValenzuelaNueva izquierda)

Nosotros tenemos un equipo de coordinación nacional. (...) Son las máximas autoridades del sector dentro del partido. Por ejemplo, yo soy vicepresidente de la Juventud y yo por derecho propio, entrecomillas, porque no hay nada escrito; por derecho propio entro a la coordinación nacional de Grandes Alamedas porque soy autoridad dentro del partido. (...)Por cada región del país nosotros tenemos coordinadores regionales que a su vez tienen sus equipos. (...) Todas (las facciones) tienen estructura, todas. Yo, por ejemplo, a nivel juventud sé con quién me tengo que juntar y con quién no me tengo que juntar. O sea, me refiero a que, si yo quiero tratar un tema importante y necesito una alianza dentro del partido, me junto con el coordinador nacional del Tercerismo. (La coordinación) de la (región) metropolitana se reúne cada quince días y de ahí llamamos a reuniones ampliadas, donde vienen todos los militantes que son cercanos a mi sector, a Grandes Alamedas, de distintas comunas. (Alan Espinoza- Grandes Alamedas)

\footnotetext{
${ }^{49}$ Vicente Espinoza y Sebastián Madrid, Trayectorias y eficacia política de los militantes en juventudes políticas, Santiago, USACH, 2010.
} 
En los testimonios se manifiesta que todo el funcionamiento del partido y de la juventud pasa por los canales y redes de "la interna" faccional. En esto existe coincidencia con la percepción de la generación socializada en dictadura, en el sentido de que sería improbable el desarrollo de una militancia activa y protagónica sin la adscripción a corrientes. De hecho, hay juicios que se repiten, como el indicar que por "subsistencia" las personas entran y se mantienen en los "lotes", pues de otro modo no sería posible acceder a participar de tomas de decisiones importantes como definir los nombres de las autoridades partidarias, determinar candidaturas a cargos de representación y distribuir puestos de confianza política. Vinculado con lo anterior, hay conciencia en que la militancia socialista se desarrolla al interior de una dinámica corporativa, es decir, el individuo no tiene peso si no es en tanto asociado con otros al interior de una facción, y es desde las facciones que se organiza y el distribuye poder. En la facción también se juegan las lealtades y su principio básico es la defensa conjunta de los intereses de "los nuestros". Para los jóvenes, en la facción están aquellos en que más se confía, los cercanos, los amigos, a menudo la familia, todos aquellos con los que se cuenta a la hora de requerir apoyo.

Es un partido que se estructura en función de lotes, por lo tanto si tú quieres acceder a posiciones de poder dentro del partido tú tienes que estar dentro de un lote. La posibilidad de hacer política fuera de esos lotes tiende a cero. (Sebastián Rivera - Renovación)

Fui (candidata) a presidenta de La Florida de la Juventud, y (me decían): "tú eres súper buena, pero pucha, no eres de ningún lote, así que pena que no van los votos pa ti”. Así que perdía. Luego mis adversarios políticos en La Florida se acercan a hablarme y (me dijeron) "Fran nosotros sabemos cómo eres, nosotros sabemos toda tu pega, todo tu trabajo, por favor vente con nosotros a trabajar, que te necesitamos acá". (Eran) de Grandes Alamedas, ahí me integré a las Grandes Alamedas porque yo también entendía que si quería entrar a la institucionalidad del partido me iba a costar muchísimo hacerlo desde fuera de los lotes. (Francisca Figueroa Grandes Alamedas)

La estructura te empuja a alguna corriente u otra. Yo creo hasta casi por un tema de sobrevivencia; no conozco un candidato que no sea de una corriente. (...) Hay cierto tipo, en el buen sentido de la palabra, de complicidad entre los sectores, de defensas corporativas. (...) O sea, si yo veo que el Tercerismo está defendiendo al candidato $\mathrm{X}$ en la comuna de Independencia, yo sé que no es porque sea un gran candidato sino porque es un Tercerista, lo mismo pa' nosotros y pa' los otros. (Cesar Valenzuela- Nueva Izquierda)

Uno trabaja en política con las personas que tienes confianza. (...)En disputas internas y cosas por el estilo efectivamente tú requieres de apoyo, y hay personas en las cuales puedes o crees que puedes confiar y personas que las que no, porque no las conoces. (Víctor Saavedra- Tercerismo) 
Si bien las facciones del PS adulto se reproducen en la estructura de la JS, ocurre que al predominar las opciones estratégicas de carácter instrumental en los acuerdos para dirigir el partido, las correlaciones de fuerza para las conformaciones de mesa directiva JS no necesariamente coinciden con las establecidas a nivel del PS. Por otro lado, en las instancias militantes de la Juventud también se conforman subgrupos que reivindican una determinada posición sobre tópicos atingentes a la especificidad del ámbito seccional juvenil (territorial, estudiantil), como ocurre en las universidades, donde colectivos socialistas autónomos de los sectores (el caso del colectivo universitario que luego se transforma en facción del PS: "Izquierda Socialista") o con más o menos cercanía a determinadas facciones, han llegado a protagonizar tensiones en donde su oposición al "otro" faccional los lleva a articular alianzas con grupos estudiantiles distintos en elecciones de centros de alumnos o federación, produciéndose el caso de que sectores socialistas lleguen a ser adversarios electorales en un espacio social estudiantil como la federación de la Universidad de Chile FECH. Si bien estos últimos han sido episodios circunstanciales y han tenido como respuesta esfuerzos reunificadores, lo claro es que nos habla de una extrema variabilidad de las lógicas de alianzas y antagonismos. En definitiva, la cultura militante asume que "la interna" no tiene una lógica estable en lo referido a las alianzas, sino que ello se juega en cada coyuntura, cuando cada ente faccional lucha por posicionarse con éxito defendiendo sus intereses y en pos de espacios de poder.

Los jóvenes entrevistados, al no tener internalizada como experiencia vivida el contexto de las corrientes del PS en dictadura, se posicionan frente al actual escenario de facciones en términos notoriamente distintos a los de la generación mayor. En general, no juzgan el actual contexto tendencial negativamente, ni tampoco expresan que la lógica presente hubiera significado la pérdida de sentidos políticos respecto a tiempos pasados. Llaman a las facciones abiertamente "lotes", pero sin la carga negativa que en ello suele ver la generación precedente, pues consideran que la organización en subgrupos, aunque no exprese mayores distinciones políticas estratégicas, sí tendría elementos identitarios de peso, al tiempo que sería un elemento primordial para la organización de la vida partidaria. Para ellos "la interna" es importante y se juegan en ella elementos de identidad. Por eso, suelen afirmar que es bueno "conocer la interna" y motivante hacerlo, pues ahí radicaría gran parte de la vida partidista a la que se optó pertenecer: "mi lote", "mi partido".

Yo asumí un cargo en la Juventud el 2010, y me tocó asumir un rol, entonces yo ya conozco la interna de la JS, que se asemeja bastante a la del Partido. Me costó, yo me vinculé el 2006, yo escuchaba nombres, sectores, corrientes, y me empezó a llamar la atención la cosa de los sectores y empecé a conocer su historia y la del sector al que yo me adscribo, del por qué existimos. (Karina Delfino- Nueva Izquierda)

A mí en lo personal me interesa mucho la operatoria interna, yo soy muy parte de la máquina, o del Partido, me gusta el Partido, me gusta la dinámica interna. (Alan Espinoza - Grandes Alamedas) 
En este marco, un momento presentado como fundamental en el relato militante del joven JS es el proceso de conocimiento e involucramiento cultural con el "lote", la asimilación de su estilo, sus códigos, su vinculación social y su historia, todo ello asociado a valores militantes que se aprecian en la facción y que refuerzan la identidad con ella. En el estilo y los códigos, hay sectores que mencionan rasgos de disciplina o de discusión interna como elementos con los cuales se identifican, del mismo modo que se destacan cuestiones como la impronta o pretensiones intelectuales de los debates y la formación. En cuanto a la inserción social, hay quienes celebran un predominio de sus cuadros en la militancia poblacional o universitaria, y así como la corriente de la Renovación y la Izquierda Socialista enfatizan en su importancia al interior de las universidades y el movimiento estudiantil, la Nueva Izquierda lo hace en relación a las comunas populares y los trabajadores. Sobre la historia de la corriente, ésta se asume como relato ejemplar de las generaciones previas y de los líderes y fundadores de cada sector, lo que implica reconocer en ella valores trascendentes e ideas fuerzas orientadoras en relación a lo que es o "debe ser" el Partido. Por lo mismo, es común que los militantes de la Renovación destaquen que su corriente histórica habría unido, como fin, democracia y socialismo, del mismo modo que los militantes de las corrientes derivadas del almeydismo destacan que su tradición fue la mayoritaria en el PS que dio la lucha contra la dictadura. Por su parte, la militancia de la corriente Nueva Izquierda suele remitirse al PS de la Unidad Popular para destacar, como dura lección aprendida, el valor del orden interno, del sentido de responsabilidad y del realismo político. Se asume que elementos como el estilo, los códigos, la historia faccional, las interpretaciones de las "enseñanzas de la historia" y la impronta de los líderes, serían los elementos principales que deslindan una corriente de otra, mucho más definitorios que los elementos ideológicos y programáticos. Primero porque lo ideológico tiende a ser visto como un ámbito ampliamente consensuado, fruto de la aceptación de la democracia como fin incuestionable del socialismo y de las formas democráticas como únicos mecanismos para acceder al poder, cuestión que, se estima, en otros momentos habría marcado diferencias entre corrientes. Segundo, porque las diferencias político programáticas estarían presentes en militantes y liderazgos, pero no serían los elementos que definan la cohesión de un sector. Tercero, porque se asume que los diagnósticos y posturas político programáticas pueden ir mutando, pero habría un sustrato cultural de "hacer política": prácticas, lógicas, valores y formas que definirían profundamente a cada facción, y que serían un potente referente de sentidos identitarios.

Una cosa que me convencía de la Renovación, cuando leía la historia del PS, era la idea de que el socialismo había que hacerlo en democracia. (...) Aquí estaba Núñez, aquí estaban otros referentes del Partido que eran tipos que habían hecho esa reflexión. (...) El diagnostico generalizado es que las tesis de la Renovación ganaron todas. (...) Hoy día un sector no tiene una opinión (político - programática). (...)Los lotes como tal no realizan un proceso de definición programática en que decidan colocarse de acuerdo. (Sebastián Rivera - Renovación) 
Hoy día entre los sectores no hay diferencias sustanciales políticamente. (Gabriel Ossandón - Izquierda Socialista)

Comienzo a ver más la historia, y efectivamente comienzo a adscribir con lo que es históricamente el PS Almeyda. (...) Siento profundo respeto por el PS que al final terminó articulando todo lo que fue el PS en la lucha contra la dictadura. (Víctor Saavedra - Tercerismo)

A mí me tocó participar, construir un espacio, donde se daba mucha importancia a la lectura, a la mirada crítica, a la cosa más analítica. (...) Hay una lógica también de reciprocidad, de fraternidad, de compañerismo, de tomar decisiones de manera mucho más horizontales y colectivas. (Daniel Melo - Colectivo de Identidad Socialista).

Yo empecé a conocer la historia del sector, empecé a saber quiénes eran nuestros líderes. (...)Conocer la historia de Camilo (Escalona), y de cómo se había forjado la Nueva Izquierda, en el sentido de las creencias de Camilo. (...) Las lealtades partidarias no se ven en todos lados y yo las vi en el líder de la Nueva Izquierda, que es Camilo; sentí que él tenía un sentido de Estado que era distinto al resto, y de ahí empecé a conocer su historia: no viene de las clases acomodadas de este país, él no tuvo oportunidades para estudiar, él vivió la clandestinidad, asumió un rol activo durante los años de Dictadura. (...)Yo ya conociendo el Partido y las dinámicas internas, creo que son bien pocas las diferencias ideológicas que se dan al interior de los sectores, yo creo que no existen grandes diferencias, hay matices. (...) Nueva Izquierda yo creo que es un sector ordenado, disciplinado. Nos juntamos, definimos cosas. (Karina DelfinoNueva Izquierda)

Fui conociendo a grupos, como vitrineando. Fue un proceso yo creo muy reflexionado (...) no era de los militantes que estaban loteados pero no lo sabían. (...)(En mi sector) pasaban cosas, no se juntaban solamente para la época de elecciones, sino que había actividades constantemente de formación. (...)La diferencia es la pretensión o la intención de reflexionar y cuestionar aquello que se da en el partido. (Felipe Jeldres- Colectivo de Identidad Socialista).

Tenía una vinculación con la militancia de base más la Nueva Izquierda que otros sectores, los comunales eran de la nueva izquierda, los vecinos eran de la Nueva Izquierda. (...) Los líderes de la Nueva Izquierda son toda gente de origen humilde, el Escalona, el Andrade. (...)Nosotros tenemos una mirada con respecto a lo que sucedió con el presidente Allende, el Partido derechamente no apoyó al presidente Allende, y esa es una cuestión que nosotros no podríamos continuar hoy día. Tenemos una concepción con respecto al sentido de la responsabilidad (...) de la importancia de las instituciones políticas. (...)Yo creo que hay mucho sentido al interior de nuestra corriente del pragmatismo, el que nuestro 
objetivo es avanzar tres, pero si podís avanzar uno, bueno, avanzái uno. (Cesar Valenzuela- Nueva Izquierda)

Yo siento que como joven y mujer adentro del tercerismo, tal vez me he podido desarrollar más que lo que hubiera podido hacer en otro sector. (...)Me he sentido súper cómoda en el sector, siento que se dan los espacios tanto para jóvenes como para mujeres. (Cecilia Lopez Tercerismo)

¿Dónde me siento yo más grato? Por así decirlo ¿Con una burguesía interna? ¿O me siento más grato con un discurso más con el obrero, con el trabajador, de quienes venimos de papás que no son profesionales? (...) Nuestra mayor concentración está en Puente Alto, San Ramón, La Cisterna, hay un tema también de clase. (Gonzalo Ramírez - Nueva Izquierda)

Buena parte de la definición del "nosotros" aparece en contraste con un "otro" faccional. Cuando la diferenciación se hace de modo más neutro, sin adjetivar negativamente, se pone acento en matices distintivos de los estilos, la historia compartida, la vinculación social, los códigos de la organización y las particulares valoraciones de las formas orgánicas. Cuando la distinción se establece en términos negativos, se señala al "otro" como culpable de los peores vicios que tendría la vida militante. Cuando ello ocurre, la percepción negativa permite resaltar, por contraste, ciertas virtudes del "lote" propio, en el sentido de considerarlo portador de un ideal socialista necesario y que se debe proyectar a la totalidad del partido. También ocurre que ciertos diagnósticos generales sobre el faccionalismo llegan a ser matizados positivamente desde cierto particularismo atribuido a la facción propia, como señalar que "los otros" protagonizan disputas sólo instrumentales (sólo por el poder) o caudillistas, relevando, por contraste, un mayor contenido político programático en "nosotros". Otro dato no menor es que la cohesión interna, incluso intergeneacional, del sector Nueva Izquierda, así como el particular énfasis de este grupo en determinadas ideas fuerza orientadoras de la acción política (el sentido de la responsabilidad como valor orientado a cuidar la alianza centro izquierdista; el pragmatismo y realismo en las consideraciones de contexto y correlación de fuerzas para la promoción de cambios), hace que sea un factor relevante de distinción entre las corrientes la percepción de cercanía o rechazo a dicha facción, al punto que varios militantes reconocen diferencias ideológicas y programáticas sólo con la corriente Nueva Izquierda.

El Tercerismo se ha caracterizado por liderazgos colectivos, es decir, no existe sólo un caudillo en particular, sino que existen muchos, muchas personas que son líderes en sus zonas geográficas y a través de consensos llegan a acuerdo. (...) Algunos (sectores) que responden a un caudillo muy poderoso tienen menor posibilidad de divergencia. (...) Al no existir caudillos fuertes, generalmente las decisiones de la Juventud (en el sector) las toman los jóvenes. Puede parecer obvio pero (...) los intereses de los 
adultos son muchas veces muy fuertes con respecto a la Juventud. En el Tercerismo eso no pasa tanto. (Víctor Saavedra- Tercerismo)

Creo que siempre la posición nuestra ha sido darle estabilidad al PS. Yo creo que de alguna forma los otros sectores han estado disponibles a no darle estabilidad al PS, o no darle estabilidad al gobierno de turno. (Cesar Valenzuela - Nueva Izquierda).

Los lotes muchas veces se han transformado en grupos clientelares. Y yo veo que hoy día el único lote que tienen un contenido político de fondo, no digo que sea muy fuerte, pero el único que tiene contenido político es el lote de Escalona (...) Es el único lote que plantea sus ideas claramente: responsabilidad política, cuidar la alianza estratégica. (...)Para mí, el lote de la Isabel Allende es un lote del poder por el poder, yo no veo un trasfondo político detrás de ella. (Santana - Nueva Izquierda)

Estamos a veces entrapados en disputas de sectores sin tener disputas programáticas detrás, entonces lo que nosotros hemos intentado siempre es poner la disputa programática por sobre la disputa personal. (Gabriél Ossandón - Izquierda Socialista)

En el caso de la Nueva Izquierda, hay una disciplina y un fanatismo acérrimo respecto a lo que se estaba desarrollando como gobierno. Su única interpretación era defender el gobierno de Bachelet $^{50} \mathrm{y}$ defender la mesa del Partido. (...) Yo soy un convencido que la Renovación, que el ethos de la Renovación ya está cumplido, por lo tanto, esa tendencia tiene una fuerte crisis de identidad, porque ya no hayan, entrecomillas, qué hacer, porque su relato, su razón de ser, ya está cumplido. (...)¿YY Grandes Alamedas? Lo que pasa es que Grandes Alamedas fue un punto de encuentro de un rechazo transversal que hubo a la Nueva Izquierda, y hasta el día de hoy carecen de una interpretación política. (...) Nosotros seguíamos, y hasta el día de hoy, seguimos bajo la misma lógica que hemos llevado siempre, dándole prioridad a la formación política, a la reflexión, a la discusión coyuntural respecto a lo que estamos viviendo. (Felipe Jeldres- Colectivo de Identidad Socialista).

Primero, nosotros somos librepensadores. O sea, esto no es un ejército. Yo creo que en el Partido hay una tendencia, la Nueva Izquierda, que está mirando desde la lógica de ejército. Segundo, que uno puede no estar de acuerdo y ser acogido y escuchado. En otros lado yo siento que no. Y lo otro, es que ha sido un sector entrecomillas joven dentro del partido, es un sector donde se da el recambio. (Alan Espinoza- Grandes Alamedas)

Con la Nueva Izquierda sí hay diferencias ideológicas más de fondo. Pero, por ejemplo, con un compañero de mi edad en la Renovación, o de

\footnotetext{
${ }^{50}$ Se refiere al primer gobierno de Bachelet.
} 
las Grandes Alamedas, no sé si haya algo que nos haga no estar de acuerdo hoy en día más allá de un pasado y lazos personales y de amistad que nos da la identidad de Colectivo. (Nicolás Zeballos- Colectivo de Identidad Socialista)

Al igual que ocurre en los adultos, el nacimiento de una facción supone generalmente un deslindamiento que apunta a relevar los aspectos políticos programáticos, lo que se describe como aspecto propio ("nuestro") en oposición con lo que se consideran lógicas predominantes del faccionalismo, es decir, aquella priorización de los objetivos instrumentales y de operatoria política (acceso y distribución de poder) por sobre un programa. En el caso de los jóvenes está menos presente esta narración de momentos fundacionales de una tendencia, pero los hay, como el caso del grupo universitario Izquierda Socialista que se conforma en tendencia del partido para dar continuidad a una identidad crítica que creció al alero de los movimientos universitarios del 2006 y 2011; o como ocurre el 2015 en el sector juvenil de la Renovación Socialista que participa de una fractura del sector y reivindica una fuerte identidad político generacional que propone posturas más decididas a favor de transformaciones estructurales. De hecho, la coyuntura reciente que va desde la elección presidencial de Michelle Bachelet hasta las elecciones internas del PS durante el 2015 han tensionado a la JS en torno a temas como el carácter e intensidad de las reformas a realizar por el nuevo gobierno, la pertinencia o no de una Asamblea Constituyente para una nueva Constitución, y el debate entre, por un lado, dar un mayor énfasis a avanzar hacia reformas estructurales cercanas a una sensibilidad de izquierda, y por otro, realizar dichos cambios en la medida en que estos articulen consensos amplios y resguardando la cohesión de la heterogeneidad centro izquierdista heredera de la Concertación de Partidos por la Democracia. La última elección en que se enfrentó Isabel Allende (respaldada por la alianza Nueva Mayoría Socialista que reunió a amplios sectores de todas las corrientes exceptuando Nueva Izquierda) y Camilo Escalona (respaldado por la Nueva Izquierda y algunos dirigentes de otras facciones), dio cuenta de esta tensión, no obstante, lo que ocurrió fue que se superpusieron ciertos clivajes político - estratégicos sobre las correlaciones entre facciones, pues gran parte de las facciones tuvieron liderazgos y militancia que apoyaron a uno u otro candidato, aunque ciertamente hubo un rotundo predominio de apoyo de la Nueva Izquierda a Escalona y un mayoritario respaldo del resto de las facciones a Isabel Allende.

En este último sentido, el diagnóstico de la militancia juvenil tiende a coincidir en que la coyuntura no permite suponer una suerte de "repolitización" de la realidad faccional a partir de cuestiones discutidas en la última elección, negándose que lo político programático fuera hoy un factor más determinante en las distinciones entre uno y otro subgrupo. Se corrobora, por tanto, un diagnóstico compartido con los adultos en el sentido de que tal tipo diferencias serían más bien transversales entre las estructuras faccionales. De todos modos, los jóvenes entrevistados coinciden en que es muy pronto para hacer vaticinios sobre eventuales cambios en las lógicas y sentidos de las facciones, pues se trataría de una historia en curso y cuyos cambios pueden ser tan rápidos como sorprendentes. 


\section{Consideraciones Finales}

El carácter del faccionalismo socialista de posdictadura, que se ha descrito en el desarrollo del artículo, es también un efecto del propio estatus de la política a partir de 1990. No es extraño que en un país en que se diagnostica "desafección” de los ciudadanos con la participación política, o "despolitización” social, un partido político vea reducido el peso de los debates político programáticos en la definición de sus subgrupos internos. Y no es extraño que se diagnostique desafección política y despolitización en un país en donde el mercado desplaza al Estado (y las disputas por su conducción) en amplios ámbitos de la configuración de lo social.

El modo en que el PS procesó el contexto de acuerdos de la transición (en parte forzados por los enclaves institucionales y el sistema electoral binominal heredados del régimen pinochetista, en parte sujetos a una hegemonía concertacionista que decidió actuar en consideración de "lo posible"), se orientó a realzar el consenso propio relativo al valor y centralidad de la democracia, pero postergando los elementos relativos a las nociones de sociedad justa en lo socioeconómico, cuestión que a fines de los años 80 ya advertía Norbert Lechner sobre las corrientes renovadoras del socialismo, que a su juicio: "privilegian la democracia política, sin mostrar similar creatividad para repensar el socialismo. (...) ¿Cómo compartir la prioridad otorgada a los procedimientos formales con la defensa de determinados contenidos, históricamente referidos a la superación de la explotación económica y la desigualdad social?" ${ }^{11}$ No podemos afirmar que, a la larga, el consenso renovador con eje en la democracia excluyera el debate partidario amplio sobre la sociedad justa, pues aquella discusión sí se dio entre los más satisfechos o descontentos con el orden producido en los gobiernos concertacionistas, sin embargo, es claro que ello no dio para convertirse en un clivaje central que marcara al partido en su organización interna expresada en el fenómeno faccional, salvo en aquellos grupos emergentes y menores que no formaban parte de las estructuras que disputaban efectivamente la dirección socialista. El punto central del presente artículo ha sido cómo este lugar devaluado del debate político programático, y su revés, la importancia de las lógicas instrumentales de organización y distribución de poder, se ha expresado en el fenómeno faccional, y particularmente, como ese fenómeno se vivencia subjetivamente en las diferentes generaciones, atendiendo al proceso histórico de cambios en el carácter del faccionalismo.

Una diferencia generacional no es igual a una diferencia etaria. Es decir, si bien es distinto el modo en que perciben la facción y sus lógicas los mayores y los jóvenes socialistas, ello no se debe a determinados atributos de la edad, sino al modo en que los sujetos incorporan subjetivamente la experiencia vivenciada en contextos diferentes, aquello que Mannheim describió como "estratificación de la vivencia" y que es clave para atender al factor generacional en la construcción histórica de una cultura militante. Efectivamente, en el PS como en otros partidos, se sedimenta una cultura política a partir de una interrelación

\footnotetext{
${ }^{51}$ Nolbert Lechner, "Los patios interiores de la democracia", Obras escogidas. Tomo 1, Santiago, LOM, $2006,362$.
} 
generacional que procesa identitariamente las transformaciones históricas de las lógicas, códigos, sentidos y significados asociados a la militancia. Para los jóvenes militantes de la JS el faccionalismo socialista de posdictadura es algo propio del partido al que ingresaron, optaron pertenecer y se identificaron, con toda la importancia existencial que tiene para el sujeto joven un proceso de identificación. Aunque en un inicio hubieran comenzado a militar "ya loteados", los jóvenes socialistas describen en su trayectoria un proceso en que se construyó la identificación con el subgrupo, proceso que se refuerza al reconocer y describir a un "otro" militante de otras facciones. Se expresa, por tanto, un involucramiento profundo con la participación en una corriente y con la dinámica actual del faccionalismo, notoriamente mayor del que se pudo captar en los testimonios de militantes de la generación adulta socializada en dictadura, y si bien los jóvenes reconocen, al igual que lo hacen los adultos, el predominio de sentidos y objetivos instrumentales (acceso a poder, influencia y cargos) en la definición faccional y en las alianzas circunstanciales entre facciones, dichos componentes no anulan un particular énfasis en aquellos elementos que hacen del subgrupo "mi lote": la historia del sector y sus valores asociados, las lógicas de acción, los estilos de militancia, las ideas fuerza orientadoras del quehacer político. Los adultos, por su parte, expresan percepciones aparentemente contradictorias: por un lado demuestran participar activamente de la vida faccional, por otro, manifiestan un mayor malestar con las lógicas y sentidos actuales del faccionalismo. Desde su mirada, ese partido del presente no es el que los comprometió durante su socialización juvenil, de modo que la diferencia profunda entre las lógicas de la militancia pasada y la presente, provoca que se exacerbe la distancia identitaria con un elemento tan fundamental como el faccionalismo.

Cabe destacar, por último, que todo diagnóstico general sobre el faccionalismo socialista debe atender a ciertos matices derivados de la tremenda heterogeneidad y complejidad del fenómeno faccional. En ese sentido, si bien se corroboran empíricamente las diferenciaciones generacionales acá expuestas, también se expresan ciertas anomalías, como el caso específico de la corriente Nueva Izquierda en donde su fuerte cohesión orgánica acentúa el elemento identitario y tiende a homogeneizar a las generaciones en sus percepciones relativas a la identidad con la facción de pertenencia y con las dinámicas faccionales en general.

Recibido: 30 septiembre 2015 Aceptado: 22 noviembre 2015

Bibliografía citada

Arrate, Jorge; Rojas Eduardo Rojas. Memoria de la Izquierda Chilena, tomo dos, Santiafo, Javier Vergara editor, 2003.

Bartels, Larry; Jackman, Dimon. “A generational model of political learning”, Electoral Studies 33, 2014. 
Bermeo, Nancy. "Democracy and the Lessons of Dictatorship", Comparative Politics 24, 1992.

Canales, Manuel; Ghiardo, Felipe; Opazo, Antonino. "Para un concepto de juventud", Pablo Cottet editor, “Juventudes. Metáforas del Chile Contemporáneo”, Santiago, Ril, 2015.

Drake, Paul. Socialismo y populismo. Chile 1936 - 1973, Valparaíso, Instituto de Historia UCV, 1992.

Espinoza, Vicente; Madrid, Sebastián. Trayectorias y eficacia política de los militantes en juventudes políticas, Santiago, USACH, 2010.

Feixa, Carles; Leccardi, Carmen. "El concepto de generación en las teorías sobre la juventud", Última Década 43, Valparaíso, CIDPA, 2011.

Fernández, Joaquín; Góngora, Álvaro; Arancibia, Patricia; “Ricardo Núñez. Trayectoria de un socialista de nuestros tiempos”, Santiago, Universidad Finis Terrae, 2013.

Gamboa, Ricardo; Salcedo, Rodrigo. "El faccionalismo en el partido socialista de Chile (1990 2006): Características y efectos políticos en sus procesos de toma de decisión”, Revista de Ciencia Política, volumen 29, número 3, Santiago, Pontificia Universidad Católica de Chile Instituto de Ciencia Política, 2009.

Garcés, Joan. Allende y la experiencia chilena. Las armas de la política, Santiago de Chile, Hueders, 2013.

Garretón, Manuel Antonio. Del pinochetismo a la sociedad democrática. Globalización y política en el bicentenario, Santiago, Debate, 2007.

Ghiardo, Felipe. "Generaciones y Juventud: una Relectura desde Manheim y Ortega y Gasset". Última Década 20, Valparaíso, CIDPA, 2004.

Gutiérrez, Eduardo. Ciudades en las sombras (una historia no oficial del Partido Socialista de Chile), Santiago, Editores Asociados, 2010.

Jobet, Julio Cesar. Historia del Partido Socialista de Chile, Santiago, Documentas, 1987.

Lechner, Norbert. "Cultura política y democratización”, Norbert Lechner Obras escogidas, tomo 2, Santiago, Lom, 2007.

Lechner, Nolbert. "Los patios interiores de la democracia", Obras escogidas. Tomo 1, Santiago, LOM, 2006

López de la Roche, Fabio. "Aproximaciones al concepto de cultura política". Convergencia número 22, Toluca, México, Universidad Autónoma del Estado de México, Facultad de Ciencias Políticas, 2000 . 
Mannheim, Karl. "El problema de las generaciones", Revista Española de Investigaciones sociológicas, número 62, Madrid, 1993.

Mella, Marcelo. "Transición y democratización durante el gobierno de Patricio Aylwin (1990 1993): La estrategia de las cuerdas separadas”, Revista Enfoques número 21, Santiago, Universidad Central, 2014.

Moulián, Tomás. Chile actual. Anatomía de un mito, Santiago, Lom, 1998.

Moyano, Cristina. MAPU o la seducción del poder y la juventud, Santiago, Ediciones UAH, 2009.

Muñoz Tamayo, Víctor. Generaciones. Juventud universitaria e izquierdas políticas en Chile y México, Santiago, Lom, 2011.

Muñoz Tamayo, Víctor. "Juventud y política en Chile. Hacia un enfoque generacional”, Última Década 35, Valparaíso, CIDPA, 2011.

Ortiz, Edison. El socialismo chileno de Allende a Bachelet. (1973 - 2005), Santiago, Alerce Talleres Gráficos, 2007.

Palieraki, Eugenia. “'La revolución ya viene! El MIR chileno en los años sesenta”, Santiago, LOM, 2014.

Peralta, Álvaro; Pistacchio, Enzo. “Duro de matar”, Santiago, Zig-Zag, 2014.

Rojas, Mauricio. 'La evolución del Partido Socialista de Chile durante la primera parte de la dictadura (1973 - 1979)”. Divergencia, número 5, Santiago, Taller de Historia Política, 2014.

Sartori, Giovanni. Partidos y sistemas de partidos, Madrid, Alianza, 2005.

Valdivia, Verónica; Álvarez Rolando; Donoso Karen. La alcaldización de la política. Los municipios en la dictadura pinochetista, Santiago, Lom, 2012.

Yocelevzky, Ricardo. "El partido socialista de Chile bajo la dictadura militar", Foro internacional, volumen 27, número 1, Ciudad de México, El Colegio de México, 1986.

Documentos citados:

Secretariado interior Partido Socialista de Chile, "Al calor de la lucha contra el fascismo, construir la fuerza dirigente del pueblo para asegurar la victoria", marzo de 1974, www.socialismochileno.org

Estatutos del Partido Socialista de Chile, Noviembre del 2003, www.pschile.cl

Partido Socialista de Chile, "Resoluciones del 24 congreso del Partido Socialista de Chile", agosto 1985, http://www.socialismo-chileno.org/ . 